Uşak Üniversitesi Sosyal Bilimler Dergisi

$2016,9 / 1$

\title{
Ortaokul Öğrencilerinin Merak, Tutum ve Motivasyon Düzeylerine Göre Fen Bilgisi Dersi Başarılarının İncelenmesi
}

\author{
Erhan CEYLAN* \\ Harun SAĞIREKMEKÇİ** \\ Erdal TATAR ${ }^{* * *}$ \\ İbrahim BİLGİN****
}

Öz

$\mathrm{Bu}$ çalışmanın amacı, ortaokul öğrencilerinin fen bilgisi dersine yönelik merak, tutum ve motivasyon düzeylerine göre fen bilgisi dersi başarılarının incelenmesidir. Çalışmanın örneklemini Hatay ilinde bir devlet ortaokulunda okuyan 180 sekizinci sınıf öğrencisi oluşturmaktadır. Nedensel karşılaştırmalı araştırma modeli esas alınarak yürütülen çalışmada veri toplamak için motivasyon ölçeği, tutum ölçeği ve merak ölçeği kullanılmıştır. Ayrıca öğrencilerin fen bilgisi dersi başarıları Temel Eğitimden Ortaöğretime Geçiş (TEOG) sınavından aldıkları fen puanları esas alınarak belirlenmiştir. Öğrenciler gruplandırıldıktan sonra gruplar arası başarı karşılaştırması amacıyla Tek yönlü varyans analizi yapılmıştır. Çalışmanın sonuçları öğrencilerin fen bilgisi dersi başarılarının, onların motivasyon düzeylerine göre bir farklılık göstermediğini ortaya koymuştur. Elde edilen veriler ayrıca fen bilgisine yönelik tutumu yüksek düzeyde olan öğrencilerin ve fen bilgisine yönelik merakı yüksek düzeyde olan öğrencilerin fen bilgisi dersi başarılarının da yüksek olduğunu göstermiştir.

Anahtar Kelimeler: Fen Bilgisi Başarısı, Merak, Tutum, Motivasyon

\footnotetext{
* Arş. Gör., Mustafa Kemal Üniversitesi Eğitim Fakültesi İlköğretim Bölümü ** Öğretmen, Mustafa Kemal Üniversitesi Fen Bilimleri Enstitüsü, Fen Bilgisi Eğitimi Anabilim Dalı

${ }_{* * * *}^{*}$ Doç. Dr., Mustafa Kemal Üniversitesi, Eğitim Fakültesi, Fen Bilgisi Eğitimi Anabilim Dalı

***** Prof. Dr., Mustafa Kemal Üniversitesi, Eğitim Fakültesi, Fen Bilgisi Eğitimi Anabilim Dalı
} 


\title{
Investigation of Middle School Students' Science Course Achievement According to Their Curiosity, Attitude, and Motivation Levels
}

\begin{abstract}
The purpose of this study is to investigate middle school students' science course achievement according to their curiosity of science lessons, level of motivation, and attitudes to the course. The sample of the study constitutes from 180 eighth grade students at a public school. The study is a causal comparative study. To collect data motivation scale, curiosity scale, and attitude scale was used. Also students' science course scores were determined on the basis of their Transition Examination from Basic Education to Secondary Education scores. One-way analysis of variance (one way ANOVA) was performed to compare achievement between groups after grouping the students. The results of the study revealed no significant differences between the students' science course achievement according to their level of motivation. The result of the study also showed that the student who have high level in the attitude and curiosity also have high level of science course achievement.

Keywords: Science Course Achievement, Curiosity, Attitude, Motivation

\section{Giriş}

Öğrencilerin başarılı olmalarında duyuşsal alan becerilerinin ne kadar önemli olduğu yapılan birçok çalışmayla ortaya konmuştur (Lee ve Brophy, 1996; Meredith, Fortner ve Mullins, 1997; Duit ve Treagust, 1998; Weaver, 1998; Alsop ve Watts, 2000; Thompson ve Mintzes, 2002). Duyuşsal beceriler ilgi, tutum, güdülenme, öz-yeterlik, inanç ve değer gibi özelliklerden oluşmaktadır. Fen eğitiminde, başarı için önemli faktörlerden olan ve duyuşsal alan içerisinde değerlendirilen tutum, motivasyon ve merak bu çalışmanın temel değişkenlerini oluşturmaktadır.
\end{abstract}

\section{Tutum}

Tutum bireyin sahip olduğu davranış şekli olarak tanımlanmaktadır (Atasoy, 2002). Bireyin bir olay veya durum karşısında göstermiş olduğu davranış şekli bir kazanım olup, sonradan öğrenilerek kazanılır ve değiştirilip geliştirilebilir (Kağıtçıbaşı, 1988; Gezer, Çokadar, Köse ve Bilen, 2006). Bireyler etkileşimde bulundukları birçok kişi, nesne ve olaya karşı tutum sahibi olabilirler (Aydın, 2007). Tutum sahibi olan kişi, o nesneye karşı olumlu veya olumsuz tepki gösterme eğilimine sahiptir ve zamanını 
düşünmekle, ilgilenmekle ve ilgili konularla uğraşmakla geçirir (Tezbaşaran, 1997).

Craker (2006), fenle ilgili tutumu "fen bilimleri hakkındaki olumluolumsuz düşünceler" olarak tanımlamaktadır. Bireyler çevreyle etkileşimi sonucu kazandığı bazı önyargılar nedeniyle fen bilimleri dersine yönelik olumsuz tutum geliştirebilmektedir. Bir çocuğun hangi konuları sevdiği hakkındaki kanaati ve kesin tutumu 11-12 yaşlarına gelene kadar gelişir. Çocuğa çevreden yanlış bilgilendirmeler yapıldığı takdirde, bu durum çocuğun fen bilgisi dersi hakkındaki düşüncelerini olumsuz yönde etkiler. Dolayısıyla öğrencilerin fenle tanışmaları, fen bilimleri dersini sevebilmeleri ve olumlu tutum geliştirebilmeleri oldukça önem arz etmektedir (Harlen, 1990; Hamurcu, 2002).

\section{Motivasyon}

Güdü; bir canlının hareketini başlatan, yönlendiren ve devam ettiren güç olup, motivasyon yani güdülenme ise belirlenen amaçlara ulaşmak amaciyla bir güç kazanma durumudur (Demirel, 2010).

Öğrencilerin öğrenme sürecinin ilk evresinde öğrenmeye yönelik güdülenmeleri büyük önem taşır. Güdülenmiş davranışlar, ilgi duyma, dikkatte süreklilik, davranışı yapmaya ve ona zaman harcamaya isteklilik ve konu üzerinde odaklanma özellikleri taşır (Fidan, 2012). Motivasyon, öğrenmeyi kolaylaştıran önemli bir etmen olup, yeterli motivasyon sağlanmadan öğretime başlanması durumunda, öğretimin verimli olmadığı gözlenmektedir (Kaya, 2001). Başarı güdüsü yüksek olan öğrenciler gerçekten öğrenmek için çalışırken, düşük olanlar ise öğrenmiş görünmeye çalışarak çaresizlik ve yılgınlık hissederler (Ataman, 2001). Motivasyonu düşük öğrenci, etkinliklerde dikkatsizleşir ve düşük notlar alarak umursamaz tavırlar sergilemeye başlar (Selçuk, 2000). Dolayısıyla motivasyon ile başarı arasında güçlü bir ilişki olduğu düşünülebilir.

\section{Merak}

Merak yeni bilgi elde etmeye yönelik, istek ve keşif amaçlı davranışları motive eden yeni duyumsal deneyim olarak tanımlanmaktadır (Litman ve Spielberg, 2003). Ayrıca merak öğrenme için bir ön şart olarak kabul edilebilmektedir (Carlin, 1999).

Fen eğitiminde öğrenmeyi etkileyen birçok faktörden biri olan merak duygusunu Harty ve Beall (1984) insanların öğrenme sürecinde önemli bir özellik ve etkileyici bir faktör olarak ifade etmiştir. Aslında fen bilgisi konuları incelendiğinde öğrencilerin merak edebileceği ve öğrenmek isteyeceği birçok konu olduğu aşikârdır. Öğrencilerin merak duygusunu 
uyarmak için etrafındaki eşya, madde ve olaylara dikkatini çekmek ve düşünmesini sağlamak gerekmektedir (Quartel, 2004). Öğrencilerin fen bilgisine karşı merakları ile ilgili yapılan bazı çalışmalarda, özellikle kızların biyoloji konularına daha çok ilgi duydukları, fizik konularının ise daha çok erkeklerin ilgisini çektiği ve yaş büyüdükçe merakın azaldığı sonucuna varılmıştır (Greenfield, 1997; Dawson, 2000; BaramTsabari ve Yarden, 2005). Ayrıca Harty, Beall ve Scharmann (1985) fen bilgisi başarısı ve merak arasında pozitif korelasyon olduğunu ifade etmişlerdir.

$\mathrm{Bu}$ çalışmanın amacı, ortaokul öğrencilerinin fen bilgisi dersine yönelik merak, tutum ve motivasyon düzeylerine göre fen bilgisi dersi başarılarının incelenmesidir. Çalışmada aşağıdaki araştırma sorularına cevap aranmıştır;

1. Ortaokul öğrencilerinin motivasyon düzeylerine göre TEOG sınavının Fen Bilgisi başarı testinden aldıkları puanların ortalamaları arasında istatistiksel olarak anlamlı bir fark var mıdır?

2. Ortaokul öğrencilerinin fen bilgisi dersine karşı tutum düzeylerine göre TEOG sınavının Fen Bilgisi başarı testinden aldıkları puanların ortalamaları arasında istatistiksel olarak anlamlı bir fark var mıdır?

3. Ortaokul sınıf öğrencilerinin merak düzeylerine göre TEOG sınavının Fen Bilgisi başarı testinden aldıkları puanların ortalamaları arasında istatistiksel olarak anlamlı bir fark var mıdır?

\section{Yöntem}

\section{Araştırma Modeli}

Araştırmada nedensel karşılaştırmalı araştırma modeli esas alınmıştır. Nedensel karşılaştırmalı araştırmalarda, araştırmacılar, bireylerden oluşan gruplar arasında belirli bir değişken açısından hâlihazırda var olan farkların nedenlerini veya sonuçlarını belirlemeye çalışır (Fraenkel, Wallen ve Hyun, 2012: 366).

\section{Örneklem}

Araştırmanın hedeflenen evrenini Hatay'daki ortaokul sekizinci sınıf öğrencileri oluşturmaktadır. Ulaşılabilir evrenini ise Hatay'ın merkez ilçesi Antakya'da 2014-2015 eğitim öğretim yılında öğrenim görmekte olan ortaokul sekizinci sınıf öğrencileri oluşturmaktadır. Amaçlı örneklem yöntemi ile seçilen ve bir devlet ortaokulunda okuyan 180 ortaokul sekizinci sınıf öğrencisi çalışmanın örneklemini oluşturmaktadır. Örneklem, şehir merkezinde bulunan ve diğer okullara nazaran daha geniş bir coğrafyadan öğrenci profiline sahip olan bir ortaokuldan seçilmiştir. Amaçlı örneklemede araştırmacılar, evrenle ilgili daha önceki bilgilere ve araştırmanın amacına 
bağlı olarak, ihtiyaç duydukları bilgiyi toplamak için örneklem seçiminde kişisel yargılarını kullanarak örneklem seçerler (Fraenkel, Wallen ve Hyun, 2012: 100).

\section{Veri Toplama Araçları}

Öncelikli olarak öğrencilere merak, tutum ve motivasyon ölçekleri uygulanmış ve alınan veriler öğrencilerin girmiş olduğu MEB tarafından yapılan Türkiye geneli TEOG başarı sınavı ile karşılaştırılarak analiz edilmiştir.

\section{Motivasyon Ölçeği (MÖ)}

Çalışmada kullanılan ölçek öğrencilerin fen bilgisi öğrenmeye yönelik motivasyonlarını belirlemek amaciyla Dede ve Yaman (2008) tarafından geliştirilmiştir. Bu ölçek 5'li Likert tipinde olup 23 maddeden oluşmaktadır. Ölçekte yer alan 5'li likert "kesinlikle katılıyorum", "katılıyorum", "kararsızım", "katılmıyorum" ve "kesinlikle katılmiyorum" şeklindedir. Ölçeğin Cronbach Alfa $(\alpha)$ güvenirlik katsayısı 0,80 olarak bulunmuştur.

\section{Merak Ölçeği (MEÖ)}

Özgün hali “Children's Science Curiosity Scale” olan bu ölçek, Harty ve Beall (1984) tarafından geliştirilmiş olup 5'li likert tipi 30 maddeden oluşmaktadır. Bunlar "kesinlikle katılıyorum", "katılıyorum", "kararsızım", "katılmıyorum" ve "kesinlikle katılmıyorum" şeklindedir. Bu seçeneklere sırasıyla 5, 4, 3, 2 ve 1 puan verilmiştir. Ölçekte yer alan sekiz negatif maddede bu puanlama analiz edilirken ters madde olarak ölçeğin Cronbach Alpha $\alpha$ güvenirlik katsayısı 0,85 bulunmuştur. Bu ölçek Serin (2010) tarafından bazı aşamalardan geçirilip Türkçeye çevrilmiştir ve ölçeğin güvenirlik katsayısı $\alpha \quad 0,87$ bulunmuştur.

\section{Fen Dersine Yönelik Tutum Ölçeği (FYTÖ)}

Fen bilgisine Yönelik Tutum Ölçeği öğrencilerin tutumlarını ölçmek amacıyla Geban vd. (1994) tarafından geliştirilmiş olup güvenirlik katsayısı 0,83 olarak bulunmuştur. Ölçek likert tipi olup Tamamen katılıyorum, Katılıyorum, Kararsızım, Katılmıyorum ve Hiç katılmıyorum şeklinde beş seçenek içeren toplam 15 maddeden oluşmaktadır. Orijinalinde kimyaya yönelik hazırlanan maddeler fen bilgisine yönelik olarak değiştirilmiştir. 


\section{Verilerin Analizi}

Çalışmadan elde elde edilen nicel veriler istatistik programı yardımı ile analiz edilmiştir. Öğrencilerin motivasyon ölçeği, merak ölçeği ve tutum ölçeğinden aldıkları puanlar belirlendikten sonra her birisine göre öğrenciler ayrı ayrı $X \pm 0,5 S S$ formülüne göre yüksek, orta ve düşük algıya sahip olanlar olmak üzere üç gruba ayrılmıştır. Bu üç grubun TEOG'dan aldıkları puanlar arasında istatistiksel olarak bir fark olup olmadığını test etmek için Tek yönlü varyans analizi kullanılmıştır. Tek yönlü varyans analizi, ilişkisiz iki ya da daha çok örneklem ortalaması arasındaki farkın istatistiksel olarak sıfırdan anlamlı bir şekilde faklı olup olmadığını test eder (Büyüköztürk, 2003: 44). Bağımlı ve bağımsız değişkenlerden elde edilen veriler için çarpıklık ve basıklık değerleri hesaplanarak aşağıdaki tabloda verilmiştir.

Tablo 1. Öğrencilerin TEOG, FYTÖ, MÖ ve MEÖ den aldıkları puanların sola ve sağa çarpıklık kat sayıları

\begin{tabular}{llc}
\hline Değişkenler & Çarpıklık & Basıklık \\
\hline TEOG & $-0,164$ & $-0,887$ \\
FYTÖ & $-0,651$ & 0,015 \\
MÖ & $-0,382$ & 0,205 \\
MEÖ & $-0,818$ & 0,265 \\
\hline
\end{tabular}

Tablo 1 de görüldüğü gibi ölçeklerden elde edilen verilerin sola ve sağa çarpık değerleri \pm 1değerleri arasında olduğundan ölçeklerden elde edilen veriler normal dağılım özelliği göstermektedir.

\section{Sonuçlar}

Çalışmanın örneklemini oluşturan ortaokul sekizinci sınıf öğrencilerinin motivasyon düzeylerine göre dağılımları ve TEOG sınavının fen bilgisi dersi başarı testinden aldıkları puanların ortalama ve standart sapma değerleri Tablo 2 de verilmiştir. 
Tablo 2. Öğrencilerin motivasyon düzeylerine göre TEOG'dan aldıkları puanların ortalama ve standart sapma değerleri

\begin{tabular}{lccc}
\hline $\begin{array}{l}\text { Motivasyon } \\
\text { düzeyi }\end{array}$ & $\begin{array}{c}\text { Öğrenci } \\
\text { Sayısı }(\mathrm{n})\end{array}$ & ss & FBBT \\
\hline 1 & 48 & 3,32 & $\mathrm{X}$ \\
2 & 75 & 3,24 & 13,94 \\
3 & 57 & 3,29 & 13,94 \\
Toplam & 180 & 3,26 & 14,35 \\
\hline
\end{tabular}

1: Düşük 2: Orta 3: Yüksek

Öğrencilerin motivasyon düzeylerine göre TEOG puanlarının ortalamalarının karşılaştırıldığı Tek yönlü varyans analiz sonuçları Tablo 3'de verilmiştir.

Tablo 3. Tek yönlü varyans analiz sonucu

\begin{tabular}{lcccc}
\hline TEOG & df & OK & F & P \\
\hline Gruplar arasi & 2 & 3,369 & 0,314 & 0,751 \\
Grup içi & 177 & 10,737 & & \\
Toplam & 179 & & & \\
\hline p $>0,05$ & & & &
\end{tabular}

Varyans analiz sonucunda öğrencilerin motivasyon düzeylerine fen bilgisi dersi başarı testinden aldıkları puanların ortalamaları arasında

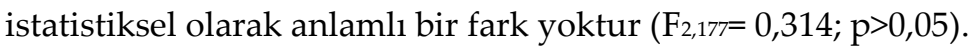

Çalışmanın örneklemini oluşturan ortaokul sekizinci sınıf öğrencilerinin fen bilgisi dersine karşı tutum düzeylerine göre dağılımları ve TEOG sınavının fen bilgisi dersi başarı testinden aldıkları puanların ortalama ve standart sapma değerleri Tablo 4 ' de verilmiştir.

Tablo 4. Öğrencilerin tutum düzeylerine göre FBBT den aldıkları puanların ortalama ve standart sapma değerleri

\begin{tabular}{lccc}
\hline $\begin{array}{l}\text { Tutum } \\
\text { düzeyi }\end{array}$ & Öğrenci & & TEOG \\
\hline 1 & Sayısı $(\mathrm{n})$ & ss & $\mathrm{X}$ \\
2 & 47 & 3,29 & 12,08 \\
3 & 71 & 2,86 & 14,54 \\
Toplam & 62 & 3,08 & 15,02 \\
\hline
\end{tabular}

1: Düşük 2: Orta 3: Yüksek 
Öğrencilerin fen bilgisi dersine karşı tutum düzeylerine göre TEOG puanlarının ortalamalarının karşılaştırıldı̆̆ı Tek yönlü varyans analiz sonuçları Tablo 5'te verilmiştir.

Tablo 5. Tek yönlü varyans analiz sonucu

\begin{tabular}{lcccc}
\hline TEOG & df & OK & F & P \\
\hline Gruplar aras1 & 2 & 128,49 & 13,782 & 0,000 \\
Grup içi & 177 & 9,323 & & \\
Toplam & 179 & & & \\
\hline p $>0,05$ & & & &
\end{tabular}

Varyans analiz sonucunda öğrencilerin fen bilgisi dersine karşı tutumlarına göre fen bilgisi dersi başarı testinden aldıkları puanların ortalamaları arasında istatistiksel olarak anlamlı bir fark vardır $\left(\mathrm{F}_{2,177}=\right.$ 13,782; $\mathrm{p}<0,05)$. Bu farkın hangi tutum düzeyinden kaynaklandığını tespit etmek için post-hoct analizi yapılmış ve sonuçlar Tablo 6 da verilmiştir.

Tablo 6. Post-hoct analiz sonucu

\begin{tabular}{lclccc}
\hline $\begin{array}{l}\text { Bağımlı } \\
\text { Değişken }\end{array}$ & $(\mathrm{I})$ & \multicolumn{5}{c}{ Ortalamalar } & Standart \\
\hline \multirow{3}{*}{ FBBT } & Düşük T & Orta T & Farkı & Hata & P \\
& & Yüksek T & $-2,46$ & 0,574 & $0,000^{*}$ \\
& & & 0,590 & $0,000^{*}$ \\
& Orta T & Yüksek T & $-0,47$ & 0,530 & 1,000 \\
\hline
\end{tabular}

$\mathrm{N}=180 ;{ }^{*} \mathrm{p}<0,05$

Tablo 6'da görüldüğü gibi yüksek düzey tutuma sahip öğrencilerle orta düzey tutuma sahip öğrencilerin düşük düzey tutuma sahip öğrencilerin FBBT puanlarının ortalamaları arasında istatistiksel olarak yüksek ve orta düzey tutumlu öğrenciler lehine istatistiksel olarak anlamlı bir fark varken orta düzey tutuma sahip öğrencilerle yüksek düzey tutuma sahip öğrencilerin FBBT puanlarının ortalamaları arasında istatistiksel olarak anlamlı bir fark yoktur.

Çalışmanın örneklemini oluşturan ortaokul sekizinci sınıf öğrencilerinin merak düzeylerine göre dağılımları ve TEOG sınavının fen bilgisi dersi başarı testinden aldıkları puanların ortalama ve standart sapma değerleri Tablo 7 de verilmiştir. 
Tablo 7. Öğrencilerin merek düzeylerine göre FBBT'den aldıkları puanların ortalama ve standart sapma değerleri

\begin{tabular}{lccc}
\hline $\begin{array}{l}\text { Merak } \\
\text { düzeyi }\end{array}$ & Öğrenci & TEOG & \\
\hline 1 & Sayısı $(\mathrm{n})$ & ss & \\
2 & 47 & 3,36 & 12,28 \\
3 & 70 & 3,14 & 14,70 \\
Toplam & 63 & 2,85 & 14,69 \\
\hline
\end{tabular}

1: Düşük 2: Orta 3: Yüksek

Öğrencilerin merak düzeylerine göre TEOG puanlarının ortalamalarının karşılaştırıldığı Tek yönlü varyans analiz sonuçları Tablo 8 'de verilmiştir.

Tablo 8. Tek yönlü varyans analiz sonucu

\begin{tabular}{lcccc}
\hline TEOG & df & OK & F & P \\
\hline Gruplar arasi & 2 & 101,91 & 10,590 & $0,000^{*}$ \\
Grup içi & 177 & 9,624 & & \\
Toplam & 179 & & & \\
\hline p $<0,05$ & & & &
\end{tabular}

Varyans analiz sonucunda öğrencilerin meraklarına göre Fen bilgisi dersi başarı testinden aldıkları puanların ortalamaları arasında istatistiksel olarak anlamlı bir fark vardır $\left(\mathrm{F}_{2,177}=10,590 ; \mathrm{p}<0,05\right)$. Bu farkın hangi merak düzeyinden kaynaklandığını tespit etmek için post-hoct analizi yapılmış ve sonuçlar Tablo 9'da verilmiştir.

Tablo 9. Post-hoct analiz sonucu

\begin{tabular}{lclccc}
\hline Bağımlı & & & Ortalamalar & Standart & \\
Değişken & $(\mathrm{I})$ & $(\mathrm{J})$ & Farkı & Hata & $\mathrm{P}$ \\
\hline \multirow{2}{*}{ TEOG } & Düşük T & Orta T & $-2,423$ & 0,585 & $0,000^{*}$ \\
& & Yüksek T & $-2,421$ & 0,597 & $0,000^{*}$ \\
& Orta T & Yüksek T & 0,0016 & 0,539 & 1,000 \\
\hline
\end{tabular}

$\mathrm{N}=180 ;{ }^{*} \mathrm{p}<0,05$

Tablo 9'da görüldüğü gibi yüksek merak düzeyine sahip öğrencilerle orta merak düzeyine sahip öğrencilerin düşük tutuma sahip öğrencilerin TEOG puanlarının ortalamaları arasında istatistiksel olarak yüksek ve orta düzey meraklı öğrenciler lehine istatistiksel olarak anlamlı 
bir fark varken orta düzey meraklı öğrencilerle yüksek düzey meraklı öğrencilerin TEOG puanlarının ortalamaları arasında istatistiksel olarak anlamlı bir fark yoktur.

\section{Tartışma ve Öneriler}

Çalışmanın sonuçları, fen bilgisine yönelik tutum düzeyi orta düzeyin üzerinde olan öğrencilerin fen bilgisi dersi başarılarının da yüksek olduğunu göstermiştir. İlgili literatürde yapılan araştırmalarda (Berberoğlu, 1990; Saracaloğlu, 1996; Kesercioğlu ve Serin, 2004; Papanastasiou ve Zembylas 2004) tutumlarla başarı arasında yüksek korelasyonlar bulunduğu belirtilmiştir. Bununla beraber başarı ile tutum arasındaki ilişkinin belirsizliğini koruduğunu söyleyen araştırmalar da bulunmaktadır (Koballa, 1995; Lewis, 2001; Mattern ve Schau, 2002).

Elde edilen bulgular, tutum değişkeninde olduğu gibi fen bilgisine yönelik merak düzeyi orta düzeyin üzerinde olan öğrencilerinde fen bilgisi dersi başarılarının yüksek olduğunu göstermiştir. Literatürde fen bilgisine yönelik -merakla ilgili yapılan- çalışmalar çok sınırlı kalmakla beraber merakın fen bilgisi başarısının önemli bir belirleyicisi olduğu yönünde sonuçlar bulunmaktadır (Harty ve Beall, 1984; Harty, Beall ve Scharmann, 1985; Serin, 2010). Çalışmadan elde edilen sonuçlar merak değişkeninin fen bilgisi başarısı için en az tutum kadar önemli bir belirleyici olabileceğini, dolayısıyla tutum değişkeninden bağımsız olarak çalışılması gerektiğini ortaya koymaktadir.

Motivasyon üzerine yapılan çalışmalar (Selçuk 2000; Kaya, 2001; Ataman, 2001) başarı ile doğrudan ilişkisi olan bir değişken olarak belirtilse de bu çalışmalarda elde edilen sonuçların aksine, yapılan bu çalışmada farklı motivasyon düzeylerine sahip öğrencilerin fen bilgisi dersi başarıları arasında anlamlı bir ilişkiye rastlanmadığı görülmüştür. Bunun sebebi olarak motivasyonu yüksek olan öğrencilerin TEOG sınavında sınav kaygısı yaşamış olabilecekleri düşünülmektedir. Bir diğer sebep olarak ta; TEOG sınavında yapılan yanlış işaretlemeler hesaplanan puanı düşürmemesi sayılabilir. Dolayısıyla bu durum motivasyonu düşük olan ve doğru seçeneği bilmediği halde rastgele işaretleyerek doğru yapanların sayısını artırmış olabilir.

Elde edilen bulgulardan hareketle ileride yapılacak araştırmalarda özellikle merak değişkeni üzerine çalışmalara yoğunlaşılması gerekmektedir. Fen bilgisine yönelik merakın fen bilgisi başarısının ne kadarlık bir bölümünü açıklayabildiği, diğer başarı belirleyicileri ile olan ilişkisi aydınlatılması gereken önemli hususlardandır. Ayrıca öğretimde kullanılacak yöntem, teknik ve hatta etkinliklerin öğrencilerin fen bilgisine 
Sosyal Bilimler Dergisi 49

yönelik tutum ve meraklarını artırıcı nitelikte hazırlanması fen bilgisi başarısı için vazgeçilmezdir.

\section{Kaynakça}

Alsop, S. ve Watts, M. (2000). Facts and Feelings: Exploring the affective domain in the learning of Physics. Physics Education, 35, 132-138.

Ataman, A. (2001). Sınıf İçinde Karşılaşılan Davranıs Problemleri ve Bunlara Karşı Geliştirilen Önlemler, Geliştirilmiş 2. Baskı, Ed. Prof. Dr. Leyla Küçükahmet, Ankara: Nobel Yayın Dağıtım.

Atasoy, B. (2002) Fen Öğrenimi ve Öğretimi. Ankara, Gündüz Eğitim ve Yayıncilik.

Aydın, O. (2007) Tutumlar (Edit: Enver Özkalp) Davranış Bilimlerine Giriş Eskişehir, Anadolu Üniversitesi

Baram-Tsabari, A. ve Yarden A. (2005). “Characterizing Children's Spontaneous Interests in Science and Technology". International Journal of Science Education, 27(7): 803-826.

Berberoğlu, G. (1990). Kimyaya İlişkin Tutumların Ölçülmesi. Eğitim ve Bilim.14, 76:16-27, Nisan.

Büyüköztürk, Ş. (2003). Sosyal Bilimler İçin Veri Analizi El Kitabı. PegemA Yayınları (3. Baskı), Ankara.

Carlin, K.A. (1999). "The impact of curiosity on learning during a school field trip to the zoo". Dissertation Abstracts International, 60 (09), 3253A.

Craker, D. E. (2006). "Attitudes toward science of students enrolled in introductory level science courses at UW-La Crosse" UW-L Journal of Undergraduate Research IX, 1-6.

Creese, M. J. (1990). “Students' Attitudes to Science Education: A Preliminary Survey". Eduational Reserach, 32 (3): 218_224.

Dawson, C. (2000). "Upper primary boys' and girls' interest in science: have they changed since 1980?". International journal of science education, 22(6): 557-570.

Dede, Y. ve Yaman, S. (2008). Fen Öğrenmeye Yönelik Motivasyon Ölçeği: Geçerlik ve Güvenirlik Çalışması. Necatibey Eğitim Fakültesi Elektronik Fen ve Matematik Eğitimi Dergisi (EFMED). 2(1), 19-37.

Demirel, Ö. (2010). Ĕ̆itim sözlüğ̈̈ (Dictionary of education). Pegem Yayıncıllk (4.Bask1), Ankara.

Duit, R. ve Treagust, D. (1998). Learning in Science: From Behaviourism Towards Social Constructivism and Beyond. (Ed: Fraser, B.,ve Tobin, K.). International Handbook of Science Education, 3-26, Kluwer Academic, UK: Dordrecht. 
Fidan, N. (2012). Okulda Öğrenme ve Öğretme. Pegem Yayınları (3. Baskı), Ankara.

Fraenkel, Wallen \& Hyun, (2012). How to Design and Evaluate Research in Education. Eighth Edition. Mc Graw Hill. New York.

Geban, Ö., Ertepınar, H., Yılmaz, G., Atlan, A. ve Şahpaz, F. (1994). Bilgisayar destekli eğitimin öğrencilerin fen bilgisi başarılarına ve fen bilgisi ilgilerine etkisi. Birinci Ulusal Fen Bilimleri Eğitimi Sempozyumu Bildiri Özetleri Kitabı. İzmir: Dokuz Eylül Üniversitesi.

Gezer, K., Çokadar, H., Köse, S. ve Bilen, K. (2006). Lise öğrencilerinin çevreye yönelik tutumlarının karşılaştırılması buldan örneği., Buldan sempozyumu. 23-24 Kasım 2006.

Greenfield, T. A. (1997). "Gender and grade level-Differences in science interest and participation". Science Education, 81: 259-276.

Harlen, W. (1990). "Primary Science", Taking The Plunge, Heinemann Books, 2-4 p., London.

Harty, H., \& Beall, D. (1984). "Toward the development of a children's science curiosity measure", Journal of Research in Science Teaching, 21 (4), 425-436.

Harty, H., Beall, D., \& Sharmann, L. (1985). Relationships between elemantary school students' science achievement and their attitudes toward sciences, interest in science, reactive curiosity, and scholastic aptitude. School Science and Mathematics, 85(6), 472-479.

Kaya, Z., (2001). "Eğitimin Psikolojik Temelleri" Öğretmen Mesleğine Giriş, Ed. Ozcan Demirel ve Zeki Kaya, Ankara: Pegem Yayıncillk.

Kağıtçıbaşı, Ç. (1988). Günümüzde insan ve insanlar: Sosyal psikolojiye giriş. İstanbul: Evrim.

Kesercioğlu, T. ve Serin, O. (2004). “Öğrencilerin fene yönelik tutum ve başarıları arasındaki ilişkinin ailesel özellikleri açısından incelenmesi" Eğitimde Yeni Yönelimler Sempozyumu, İzmir.

Lee, O. ve Brophy, J. (1996). Motivational Patterns Observed in Sixth-Grade Science Classrooms. Journal of Research in Science Teaching, 33(3), 585610.

Litman, J.A., ve Spielberger, C.D. (2003). "Measuring epistemic curiosity and its diversive and specific components". Journal of Personality Assessment, 80 (1), 75-86.

Meredith, J. E., Fortner, R. W., ve Mullins, G. W. (1997). Model Of Affective Learning For Nonformal Science Education Facilities. Journal of Research in Science Teaching, 34(8), 805-818. 
Quartel, P. (2004). "The importance of curiosity and openness". Teaching Science, 50 (3), 31.

Papanastasiou, E. C.ve Zembylas, M. (2004): Differential effects of science attitudes and science achievement in Australia, Cyprus, and the USA, International Journal of Science Education 26, 3:259-280.

Saracaloğlu, A. S. (1996). Beden Eğitimi Öğretmeni Adaylarının Duyuşsal Giriş Özellikleri İle Yabancı Dil Başarısı Arasındaki İlişki. Performans. 2,4: 145-158.

Selçuk, Z., (2000). Sinıf içi rehberlik uygulamaları, Ankara: Pegem Yayıncılık.

Serin, G. (2010). İlköğretim 7. Sınıf Öğrencilerin Fene Karşı Meraklarının İncelenmesi, Mustafa Kemal Üniversitesi Sosyal Bilimler Enstitüsü Dergisi, 7(13), 237 - 252.

Tezbaşaran, A. A.(1997) "Likert Tipi Ölçek Gelistirme Kılavuzu” Ankara: Türk Psikologlar Dernegi Yay.

Thompson, T. L. ve Mintzes, J. J. (2002). Cognitive structure and the affective domain: On knowing and feeling in Biology. International Journal of Science Education, 24(6), 645-660.

Weaver, G. C. (1998). Strategies in K-12 Science instruction to promote conceptual change. Science Education, 82(4), 455-472. 
E. CEYLAN, H. SAĞIREKMEKÇİ, E. TATAR, İ. BILGGIN $\mid 52$ 